\title{
Construções completivas insubordinadas subjetivas-modais no português brasileiro
}

DOl: http://dx.doi.org/10.21165/el.v49i1.2675

\section{Flavia Bezerra de Menezes Hirata-Vale'}

\section{Resumo}

Neste trabalho descrevem-se e analisam-se os usos de construções completivas insubordinadas (CCI) no português brasileiro com função subjetiva-modal, de acordo com as propostas de Evans (2007, 2009), Van Linden e Van de Velde (2014), D'Hertefelt, (2015), Gras (2016), Sansiñena (2015), entre outros. As ocorrências foram coletadas em diferentes corpora de língua falada (Corpus do Português, Corpus Brasileiro, Corpus C-Oral e IBORUNA). Nas construções subjetivo-modais, o falante expressa sua atitude subjetiva em relação à proposição. As CCls sempre são formalmente marcadas com o modo subjuntivo, têm natureza exclamativa ou optativa/hortativa, e os sujeitos são de terceira pessoa, singular ou plural. No uso de CCls ocorre uma extensão funcional na medida em que essas construções expressam relações além do nível de oração, que podem ser avaliadas apenas discursivamente.

Palavras-chave: insubordinação; construções completivas; função subjetivo-modal.

1 Universidade Federal de São Carlos (UFSCar), São Carlos, São Paulo, Brasil; fbmhvale@gmail.com; http://orcid.org/0000-0002-9091-9461. 


\title{
Subjective-modal insubordinate completive constructions in Brazilian Portuguese
}

\begin{abstract}
In this paper, the uses of insubordinate complete constructions ( $\mathrm{Cl}$ ) in Brazilian Portuguese with subjective-modal function are described and analyzed according to the proposals of Evans (2007, 2009), Van Linden and Van de Velde (2014), D'Hertefelt, (2015), Gras (2011, 2016), Sansiñena (2015), among others. Occurrences were collected in different corpora spoken language (Corpus do Português, Corpus Brasileiro, Corpus C-Oral and IBORUNA). In the subjective-modal constructions, the speaker expresses her/ his subjective attitude regarding the proposition. ICCs are always formally marked by the subjunctive and have an exclamatory or optative/hortative nature, and the subjects are third-person singular or plural. In conclusion, in the use of ICCs there is a functional extension, as these constructions express relationships beyond the sentence level, which can only be evaluated discursively.
\end{abstract}

Keywords: insubordination, completive constructions, subjective-modal function.

\section{Introdução}

Muitos são os trabalhos que recentemente têm como foco de análise construções complexas consideradas como não canônicas, não previstas nas gramáticas tradicionais e pouco exploradas nos manuais de linguística descritiva formalistas. Neste artigo, descreve-se e analisa-se, para o português brasileiro, um fenômeno linguístico particular, que também diz respeito ao uso não-prototípico das construções complexas: os casos de construções que, embora apresentem uma marca qualquer de subordinação, são usadas independentemente, sem que estejam conectadas a uma oração principal, como se vê nos exemplos seguintes, do alemão, inglês, holandês, espanhol e português:

(1) Wenn Sie sich vielleicht die Hände wasch-en mÖchten?

if you self perhaps the hands wash-inf might. (EVANS, 2007, p. 373).

Se você pudesse lavar suas mãos.

(2) That he should have left without asking me! (EVANS, 2007, p. 403).

Que ele tenha saído sem me pedir!

(3) zarra> tenshin: ga ze daar eens uit hun bed halen

$<$ Tenshin> no way

$<$ Tenshin> dat ze het alleen doen

'Z: Tenshin, go and get them out of bed! T: No way. They should do it all by themselves!' (VAN LINDEN; VAN DE VELDE, 2013, p. 10)

Z: Tenshim, vá e tire-os da cama. T: Não. Que eles têm que fazer tudo sozinhos. 
(4) (duas amigas estão conversando sobre o seu peso] J02: he engordado (.) es que yo me siento más gorda es que es verdade

J01: [que yo no te veo más gorda . yo te veo perfecta tía como antes]

J02: [no he engordado] (SANSIÑENA, 2015, p. 109).

(5) $\quad{ }^{*} \mathrm{CEL}$ : o GoldWave é massa / que cê <po' falar> com ele assim / ô / eu quero que segmenta de xis em xis minuto //

*HEL: <ahn> // ham <ham> // (CORPUS C-ORAL).

Essas construções têm sido geralmente chamadas de insubordinadas, porque passam por um processo de insubordinação, um termo cunhado por Evans (2007) para designar o processo pelo qual se formam construções que são usadas de modo convencionalizado como orações principais, mesmo que à primeira vista pareçam ser formalmente subordinadas.

As construções insubordinadas realizam estratégias discursivo-pragmáticas específicas, assumindo um papel importante na constituição textual e interacional (EVANS, 2007; MITHUN, 2008; VERSTRAETE; D'HERTEFELT; VAN LINDEN, 2012; GRAS, 2016; VAN LINDEN; VAN DE VELDE, 2014; VERSTRAETE; D'HERTEFELT, 2016; D'HERTEFELT, 2015, SANSIÑENA; DE SMET, CORNILLIE, 2015a, SANSIÑENA; DE SMET; CORNILLIE, 2015b, SANSIÑENA, 2015, HIRATA-VALE, 2015, entre outros).

Neste trabalho analisam-se especificamente as construções completivas insubordinadas ${ }^{2}$ no português brasileiro, encabeçadas pela conjunção integrante que, um item multifuncional, não só no português, como também o são os seus congêneres, no espanhol e no holandês. As construções analisadas consistem em um desafio teóricoanalítico, uma vez que, embora ainda apresentem algumas características de uma oração subordinada, como uma conjunção completiva, ou a atualização de determinadas correlações modo-temporais, ou mesmo uma ordenação de constituintes específica, não se comportam como tal, no sentido de que elas parecem sintática, semântica e pragmaticamente completas. As CCls, pode-se dizer, tornam dispensável uma oração matriz, algo que não se esperaria em orações completivas, e funcionam de modo independente.

Este trabalho organiza-se da seguinte forma: a primeira seção dedica-se a apresentar os pressupostos teóricos para a definição do que é o processo de insubordinação. $\mathrm{Na}$ sequência, são discutidos aspectos específicos das construções completivas insubordinadas nas línguas. Na seção seguinte, passa-se à descrição e análise das

2 Considera-se construções como um par forma/sentido cujo significado não será estritamente computado a partir de significados isolados dos elementos da Forma ou do Sentido que as integram. Segundo Goldberg (1995, p. 4), "as construções são as unidades básicas da linguagens". 
ocorrências de construções completivas insubordinadas no português brasileiro, de um ponto de vista interacional e construcional. Por fim, apresentam-se as considerações finais.

\subsection{As construções insubordinadas: pressupostos teóricos}

Como já se mencionou, construções insubordinadas têm sido tratadas em uma variedade de línguas, inclusive no português brasileiro (HIRATA-VALE, 2015, 2017, HIRATA-VALE; OLIVEIRA; SILVA 2017; PIRES; CORADINI, 2018), trabalhos nos quais se propôs uma descrição de construções condicionais insubordinadas, adotando como base teórica especialmente os trabalhos de Evans (2007), Mithun (2008), D'Hertefelt (2015) e Sansiñena (2015).

Outros trabalhos de cunho funcionalista também se dedicaram à análise desse tipo de construção, sem, no entanto, denominá-las de insubordinadas. Para o português brasileiro, podem-se destacar os trabalhos de Decat $(1993,2011)$ e de Stassi-Sé $(2012)$.

Decat $(1993,2010,2011,2012)$ considera que essas construções são orações desgarradas, ou seja, que "ocorrem sem a oração matriz, à maneira de um enunciado independente" (DECAT, 2010, p. 167), como em:

(6) Imagine viver sem fronteiras. Poder estar sempre perto de quem você gosta. Mesmo daqueles amigos mais distantes. Imagine poder ir a qualquer lugar. E até estar em dois lugares ao mesmo tempo. Não ter limites. Não ver distâncias. Esse jeito de viver existe. Basta usar o seu celular. [...] (DECAT, 2012, p. 159).

Decat (2011) analisa orações adverbiais e adjetivas, e considera que o desgarramento de uma oração completiva só acontece se a completiva já tiver sido usada como encaixada anteriormente, e é então repetida pelo falante, parafrasticamente, ao longo do enunciado como uma desgarrada. Considera-se que os tipos de construção que ora se analisam, como se vê nos exemplos de (1) a (5) não fazem parte do escopo de pesquisa de Decat.

Especificamente a partir do ponto de vista da Gramática Discursivo-Funcional (GDF), Stassi Sé (2012) descreve esse tipo de construção como orações independentes, e as chama de subordinadas discursivas, entendidas como grandes porções textuais, os Moves, que, apesar de apresentarem a forma de uma oração subordinada, não dependem de qualquer cláusula anterior ou posterior, e, além disso, são entoacionalmente destacadas por pausas, Atos Interativos, ou por ambos. Segundo a autora, essas orações não apresentam dependência morfossintática, como no exemplo a seguir: 
(7) nós protegíamos estas crianças devido também ao, à boa parte de caridade que nós temos, não é, o amor, não é assim, bem, bem elevado, se eu posso dizer, porque, eh, eu, aconteceu o problema do, duma menina, esqueço o nome, [...] (Ang97:Meninos de Rua)

Stassi-Sé defende que essas construções desempenham uma Função Interacional, como no exemplo a de salvaguarda, que é diferente das funções relacionadas a outras camadas nos Níveis Interpessoal e Representacional, tais como, as funções retóricas e as funções semânticas. A autora também não trata das orações completivas.

Embora esses trabalhos versem sobre orações que poderiam ser consideradas como insubordinadas, nenhum deles se concentra exclusivamente e efetivamente em construções completivas insubordinadas.

No que diz respeito ao processo que dá origem a uma construção insubordinada, Evans (2007) foi o primeiro autor a destacar o estudo de construções que, embora ainda apresentem algumas características de uma oração subordinada, não se comportam como tal, no sentido de que elas parecem sintática, semântica e pragmaticamente completas.

A proposta de Evans (2007) segue um ponto de vista diacrônico e se baseia no processo de elipse. Segundo o autor, a construção insubordinada resulta de um processo que vai desde a elipse da oração principal em uma construção anteriormente subordinada até o uso convencionalizado da oração subordinada como principal, que é então analisada como uma construção independente. Evans (2007) também elenca uma série de funções discursivas das construções insubordinadas, tais como, controle interpessoal, modalização e sinalização de material pressuposto.

Embora a proposta de Evans (2007) seja a mais conhecida dentre aqueles que trabalham com o tema da insubordinação, é justo mencionar que ela não é unânime. De fato, é uma proposta que suscita alguma controvérsia. O principal ponto que vem sendo questionado diz respeito à utilização do processo de elipse para explicar a origem de uma construção insubordinada. Ao trabalho pioneiro de Evans (2007) seguiram-se as propostas de Mithun (2008), D'Hertefelt e Verstraete (2013), Van Linden e Van de Velde (2014), Sansiñena, de Smet e Cornillie (2015a, 2015b), entre outros. Nesses trabalhos, nota-se que as explicações para a gênese do processo de insubordinação ou "independentização" de uma oração completiva podem ser de diferentes ordens. No entanto, de um modo geral, todas essas propostas consideram que nesse processo há uma mudança no escopo de atuação dessa construção, que passa do nível da oração complexa para contextos mais extensos, da sintaxe para a pragmática e, como tal, se configura como uma expansão do alcance da construção insubordinada ou independente, que expressa não apenas sentidos proposicionais, mas também interpessoais (estratégias de polidez, preservação de face, entre outros). 


\section{As construções completivas insubordinadas (CCls)}

Em relação às construções completivas insubordinadas, neste trabalho apresentamse sucintamente as propostas de Gras $(2011,2016)$ e Sansiñena (2015), a respeito das orações insubordinadas completivas com que no espanhol (peninsular e latinoamericano), assim como as de D'Hertefelt (2015) e de Verstraete e D'Hertefelt (2016) para línguas germânicas.

Gras (2016) trata de orações encabeçadas pelo que em espanhol peninsular. O autor adota uma proposta construcional-interacional e considera que essas orações podem ser usadas para expressar diferentes funções interacionais, tais como, ordens (no imperativo em terceira pessoa), optativas, modalidade avaliativa, sentenças-eco, autorrepetição, entre outras.

Gras (2016) discute se a classificação de Evans (2007) daria conta das orações com que inicial em espanhol, dada a gama de possibilidades funcionais que essa língua apresenta. Nesse sentido, Gras (2016) apresenta uma tipologia das insubordinadas completivas para o espanhol, e considera que essas construções têm duas macrofunções: subjetivasmodais e conectivo-discursivas, que englobariam todo o vasto espectro funcional encontrado na literatura a respeito de insubordinadas completivas.

As subjetivas-modais são aquelas que expressam ordens (8) e desejos (a "desejabilidade" de um resultado), exclamações (contra-expectativa e avaliação (9)) como em:

(8) pos/ ir ahora 1 y si no está/ vais al ambulatorio

'so/ you go now $\uparrow$ and if (she) is not there/ you go to the hospital'

$\begin{array}{llll}\boldsymbol{y} & \text { que } & \text { te } & \text { pinch-e } \\ \text { and } & \text { that } & \text { you.SG.OBJ } & \text { poke-3SG.PRS.SBJV (GRAS, 2016, p. 135). }\end{array}$

(9) $\mathrm{S}$ : janda que le duel-an los pies!

INTERJ that REFL hurt-3PL.PRS.SBJV the feet

'May her feet hurt!' (LAUGHS) (GRAS, 2016, p. 135).

No caso das construções insubordinadas que têm uma função de conexão discursiva, elas estabelecem relações lógicas ou retóricas com a oração e o contexto precedente, tais como, contraste, reiteração, justificativa, background, etc., como no exemplo seguinte:

(10) G: (bue)no ¿y ahora por dónde nos vamos a ir?

'well and now which way should we take?'

'where?'

L: iadónde?

G: ¿que por dónde nos vamos ir? 
that for where 1PL.OBJ go.1PL.PRS.IND go.INF

'I said which way should we take' (GRAS, 2016, p. 134).

A diferença funcional entre esses dois tipos de construção reside no fato de que as primeiras admitem mecanismos de combinação entre orações enquanto as segundas não, de modo que não podem ser coordenadas ou subordinadas a nenhum tipo de oração.

Ao adotar uma perspectiva construcional, Gras (2016) assume que o que inicial não é apenas um item polissêmico no espanhol, mas sim que ele encabeça duas construções distintas, que têm não apenas significados como também propriedades formais e discursivas diferentes. Além disso, o fato de Gras (2016) aliar à sua análise uma proposta interacional torna seu trabalho ainda mais rico, na medida em que considerações a respeito das informações contextuais e pragmáticas das unidades discursivas aportam novas possibilidades explicativas.

Sansiñena (2015), por sua vez, considera que as insubordinadas completivas cumprem uma gama de funções discursivas e interacionais, e são usadas para expressar ordens, direções, desejos (construções imperativas (11)), avaliações, comentários (construções exclamativas (12)), e elaborações (construções conectivas (13)), como nas seguintes ocorrências:

(11) G02: con el auto el auto de mi papá también huevón casi le pegaron al Pedro

\begin{tabular}{lllll} 
G03: & que & \multicolumn{1}{c}{ te } & lo prest-e \\
& COMP & you.DAT.SG it & lend-PRS.SBJV.3SG \\
para & i-r & a & otro lado & \\
to & & go-INF to & another place (SANSIÑENA, 2015, p. 62).
\end{tabular}

(12) Comment on a profile picture of a young woman on Twitter

@AndreaObaid que estai bonit-a Andreita

COMP be.IND.PR.2SG beautiful-FM.SG Andreita

(SANSIÑENA, 2015, p. 89).

(13) [Two friends talking about their weight]

J02: he engordado (.) es que yo me siento más gorda es que es verdad

J01: [que yo no te veo más gorda . yo te veo perfecta tía como antes]

J02: [no he engordado] (SANSIÑENA, 2015, p. 109).

Sansiñena (2015) testa o grau de insubordinação das completivas com o que átono, uma vez que esses casos ainda apresentariam alguma relação de dependência com uma informação previamente mencionada, e desse modo não seriam construções insubordinadas prototípicas, nos termos de Evans (2007), configurando-se como casos de extensão da dependência (MITHUN, 2008) ou de mudança de dependência (VERSTRAETE, 2007), no qual a dependência se percebe discursivamente. 
Assim como Gras (2011, 2016), a autora adota uma perspectiva construcionalinteracional, mas reconhece três tipos de insubordinadas completivas. A diferença em relação à análise de Gras (2016) diz respeito ao fato de que Sansiñena (2015) inclui em seu trabalho a descrição de variantes latino-americanas, da Argentina e do Chile, o que sem dúvida leva a uma análise mais ampla do fenômeno em questão, uma vez que as variantes não europeias apresentam usos diferentes daqueles do espanhol peninsular.

D'Hertefelt (2015) e Verstraete e D'Hertefelt (2016) analisam, em trabalho tipológico, orações insubordinadas completivas em holandês, inglês, alemão, sueco, dinamarquês e islandês. Os autores consideram que, nessas línguas, as insubordinadas são usadas para expressar desejos, ordens ou conselhos (deônticas (14)), avaliações (15), asserções (16), e elaborações (17), como nos exemplos seguintes:

(14) DUTCH (IC)

Hellehond koest, lig, in uw kot en

Hellhound [nickname] quiet, down, into your kennel and

$\begin{array}{lllll}\text { Dat } & \text { ik } & \mathrm{u} & \text { niet meer } & \text { hoor. } \\ \text { COMP I } & \text { you } & \text { NEG } & \text { anymore } & \text { hear.PRS }\end{array}$

don't let me hear you again! [lit.: that I don't hear you again!] (D'HERTEFELT, 2015, p. 34).

(15) ICELANDIC (Petersson 2011: 206)

$\begin{array}{llll}\text { Ad } & \text { Maria } & \text { skuli vera } & \text { hér! } \\ \text { COMP } & \text { Maria } & \text { shall.PRS.SBJV be.INF } & \text { here }\end{array}$

[I'm amazed] That Maria should be here! (D'HERTEFELT, 2015, p. 46).

(16) SWEDISH (Delsing 2010: 34)

A: Du är förtjust i Lisbet. You are fond of Lisbet.

$\begin{array}{llll}\text { B: } & \text { ATT jag det är! } \\ & \text { COMP । } & \text { DEM be.PRS }\end{array}$

I sure am! [lit.: THAT I am!] (D'HERTEFELT, 2015, p. 55).

(17) DUTCH (CGN)

A: heb je zelf wel 'ns een scan gehad

have you ever had a scan yourself

B: nee

no

$\begin{array}{llllll}\text { A: } & \text { dat } & \text { je } & \text { in } & \text { zo'n apparaat } & \text { gaat } \\ & \text { ComP } & \text { you } & \text { in } & \text { such.a machine } & \text { go.PRS }\end{array}$

(D'HERTEFELT, 2015, p. 59).

De acordo com os autores, apenas as construções deônticas, avaliativas e assertivas podem ser analisadas como insubordinadas. As construções elaborativas ainda apresentam algum traço de dependência com o contexto precedente, o que os faz 
considerar que nessas construções ocorre um processo de mudança de dependência, nos termos de Verstraete (2007) e D'Hertefelt e Verstraete (2014). Nesse sentido, os autores concluem que o fato de as construções completivas elaborativas serem as únicas atestadas produtivamente nas línguas em análise deve ser considerado como um indício de que esse tipo de mudança é mais "regular" em diferentes tipos de construções, no amplo domínio da subordinação e não está restrito aos casos de insubordinação, nos termos de Evans (2007). Para Verstraete e D'Hertefelt (2016), as mudanças de limites de dependência representam um processo pragmaticamente motivado, que, desse modo, gera resultados mais uniformes translinguisticamente.

Desta breve apresentação, percebe-se que todos os autores não apenas propõem uma classificação discursivo-funcional das construções completivas insubordinadas como também buscam alternativas à análise proposta por Evans (2007), seja em relação a uma única língua seja de um ponto de vista tipológico. Neste trabalho pretende-se mostrar que também no português brasileiro essas construções podem ser analisadas nesses domínios funcionais, expressando valores subjetivos e intersubjetivos, atrelados a diferentes configurações formais.

\section{Descrição e análise dos dados}

A análise que ora se apresenta parte de dados coletados em corpora gratuitos disponíveis on-line: Corpus do Português (www.corpusdoportugues.org) ${ }^{3}$ e o Corpus Brasileiro (http:// corpusbrasileiro.pucsp.br/cb/Inicial.html), e IBORUNA (http://www.iboruna.ibilce.unesp. br/), além do Corpus C-Oral (www.c-oral-brasil.org). Foi realizada uma busca automática nos corpora em que essa ferramenta estava disponível (Corpus do Português e Corpus Brasileiro), e manual quando não havia essa opção (IBORUNA e Corpus C-Oral), pela conjunção integrante que. Em seguida, procedeu-se a uma análise de cunho qualitativo para caracterizar as CCls sintática, semântica e pragmaticamente. Foram analisados fatores de ordem formal, tais como, o modo temporal nessas construções, o tipo de ilocução, o tipo de sujeito e a presença/ausência de um ouvinte. Discursivamente, as CCls foram avaliadas em relação ao papel que desempenham nas interações verbais e as funções por elas assumidas na língua.

Seguindo a proposta de Gras (2016), assumiu-se uma abordagem construcional-interacional, assim como o faz Sansiñena (2015). Acredita-se que é possível, assim, dar conta dos aspectos construcionais das CCls e ainda revelar o papel dessas construções no processo de interação, em textos escritos e orais. Acredita-se que a análise construcional permite observar que diferentes (sub)tipos semânticos estão pareados com distintas marcas formais, como afirma Goldberg (1995).

3 Foram utilizadas apenas ocorrências do português brasileiro. 
A análise dos corpora mostra que há dois tipos de CCls no português: as construções subjetivas-modais e as construções conectivas-textuais. Neste trabalho, o escopo de análise se restringe às considerações relativas apenas às construções subjetivas-modais (HIRATA-VALE, 2018).

De um ponto de vista discursivo-funcional, nas construções subjetivas-modais, o falante expressa sua atitude subjetiva em relação à proposição. O falante usa a CCI para formular desejos, pedidos, ordens, ou seja, para exprimir seus sentimentos, crenças e predicações emocionais ou enfáticas, como se vê nas ocorrências seguintes:

(18) Quando estiver pronto pra segurar Vinte e Cinco, eles não vão me encontrar fácil. Por isso quero tirar Janaína e a menina daqui. Que fiquem longe. (CdP).

(19) Inf.: só que a reação vai tê(r) que sê(r) por mim Cássio [Doc.: uai] e não por ela Doc.: tudo bem uai

Inf.: cê entende?

Doc.: que seja

Inf.: e que eu vô(u) tê(r) que/ só que na verdade eu vô(u) tê(r) que lutá(r). (IBORUNA/AI_011).

(20) Espero que fique esclarecido sobre isto! Memórias: respeito todas as suas opiniões, todos os seus comentários, todas as suas críticas, todas as suas ideias e por as respeitar estou sempre disposto a debater serenamente tudo o que transmita, com elevação e dignidade. NÃO LHE ADMITO ATAQUES PESSOAIS. Que fique isso também bem claro. Por favor não volte a baixar 0 nível do debate. (CdP).

Nas ocorrências (18) e (19), o falante expressa um desejo, que pode ser entendido como uma consequência ou uma reação em relação ao conteúdo anteriormente expresso. Desse modo, em (18), o falante, ao dar conta de uma situação de perigo, deseja que as duas personagens mencionadas fiquem longe de onde ele está. Em (19), o documentador reage à afirmação do informante, que afirma que vai ter que tomar uma determinada atitude em relação à sua dissertação, por meio de uma insubordinada completiva modal, expressando não apenas um desejo, mas também uma constatação. Em (20), considerase que o falante esteja emocionalmente envolvido na situação, e escolhe uma construção insubordinada subjetiva-modal para expressar de forma enfática o seu ponto de vista.

Do ponto de vista formal, foram analisados fatores como o modo temporal realizado nessas construções, o tipo de ilocução, o tipo de sujeito e a presença/ausência de um ouvinte, critérios elencados em Gras (2016).

Nesse sentido, pode-se dizer que as construções subjetivas-modais sempre são formalmente marcadas com o modo subjuntivo, apresentando ainda uma natureza exclamativa (21) ou optativa/hortativa (22): 
(21) Concordo com você... era tão discreta, fazia questão de não aparecer com o Rob, q era seu namorado, solteiro... mas não pensou 2 vezes em ficar na rua se esfregando com um cara casado....... Que fosse pra um motel pelo menos!!!! (CdP).

(22) Tá... devo admitir que eu nunca me imaginei usando aliança de casamento, muito menos ao estilo tradicional (é que eu acho meio brega, rsrs), mas já que estamos nos casando de verdade e oficialmente, que venham as alianças! Mas que venham em outro branco... porque alianças tudo bem, mas douradas já é demais! (CdP).

Nos dois casos, as CCls expressam uma atitude subjetiva do falante. Os sujeitos são de terceira pessoa, singular ou plural. Embora se possa dizer que em ambos os casos se expresse um desejo do falante, em (21), a construção parece não pressupor um destinatário, mas revela apenas a admiração do falante em relação à situação. O falante parece fazer uma avaliação e ao mesmo tempo expressar um desejo. Há um grande envolvimento emocional do falante, e o ouvinte é apenas uma testemunha do que o interlocutor expressa, o que significa que não se espera a reação dele sobre o que foi dito. Em (22), o falante indica para o ouvinte seu desejo de que a situação apresentada se torne realidade, nesse caso, de que as alianças sejam usadas, mesmo que nunca pensasse que isso fosse possível em sua vida. Nesse sentido, é o uso do subjuntivo que leva a essa possibilidade de interpretação subjetiva-modal, constituindo, portanto, um aspecto formal imprescindível para a realização dessa função.

Há que se destacar que uma análise prosódica das completivas insubordinadas no português éessencial, tal como a de García (2016) para o espanhol peninsular de diferentes regiões. Em seu trabalho, a autora se vale da descrição prosódica para diferenciar as construções insubordinadas, de modo a testar as distinções propostas por Evans (2007) para os diferentes tipos de insubordinadas, de acordo com o grau de convencionalização da oração subordinada e, desse modo, estabelecer o nível de (in)dependência sintática dessas construções. Esse seria mais um critério formal para a discriminação entre os tipos de vínculos entre as orações e suas funções ${ }^{4}$. Assim, trabalhar com prosódia é uma tarefa que se apresenta no horizonte de pesquisa, e que corroboraria a análise ora apresentada.

\section{Considerações finais}

Neste trabalho analisaram-se as construções completivas insubordinadas subjetivasmodais, no português do Brasil, a partir de uma abordagem construcional-interacional, e considerou-se que essas construções têm importância no plano discursivo, não se tratando apenas de meras variantes de orações subordinadas completivas "plenas". É importante mencionar que o português do Brasil não apresenta tantos contextos de uso

4 Silvestre (2017) analisa prosodicamente alguns tipos de orações "desgarradas" (condicionais, temporais, finais, e concessivas) no PB e no PE. No entanto, a autora não faz uma classificação dessas orações no que diz respeito às suas funções discursivas, não atentando, pois, às diferenças entre os tipos de construções dos pontos de vista formal e funcional, e, além disso, restringe-se às adverbiais. 
de insubordinadas completivas como o espanhol, tal como se vê no trabalho de Sansiñena (2015). Ao contrário, o português parece ter um padrão de ocorrências semelhante ao do inglês, que, segundo Verstraete e D'Hertefelt (2016), tem menos tipos de insubordinadas completivas em comparação com as outras línguas germânicas por eles estudadas. Por essa razão, parece ser possível considerar que as construções insubordinadas no espanhol estão mais bem estabelecidas no sistema linguístico dessa língua, o que poderia configurar que nessas línguas as construções em processo de insubordinação encontram-se em diferentes estágios de construcionalização, de acordo com o cline proposto por Evans (2007).

As construções completivas insubordinadas no português brasileiro consistem em construções em que se nota uma extensão funcional do domínio de atuação dos marcadores de subordinação, nesse caso da conjunção integrante, para desempenharem funções em níveis além da oração. Desse modo, pode-se dizer que outrora dependentes, essas estruturas são agora usadas como construções independentes, passando a ter uma finalidade que é apenas avaliada em termos discursivo-interacionais, e não propriamente em termos sintáticos, de simples conexão. Nesse sentido, pode-se considerar que o elemento "subordinador" deixa de funcionar um subordinador e assume outras funções, de cunho discursivo.

Acredita-se que, a partir da adoção de uma perspectiva construcional-interacional, é possível entender o funcionamento das CCls em situações de interação social, e sua pertinência em uma possível rede construcional de (in)subordinação (GOLDBERG, 1995, 2005), que aos poucos vai sendo elaborada para o português brasileiro (COIMBRA, 2020; CORADINI, 2020; ALVES, 2020; HIRATA-VALE, 2017, 2018, 2020).

\section{Agradecimentos}

Este artigo é decorrente de projetos FAPESP 2013/24523-2, 2015 e FAPESP 2016/05224-2.

\section{REFERÊNCIAS}

ALVEZ, C. P. Construções condicionais insubordinadas adversativas: uma análise descritiva no português do Brasil. Relatório de Iniciação Científica. FAPESP, Processo n. 2017/15225-9. São Carlos, 2020.

COIMBRA, E. C. Construções semi-insubordinadas no português brasileiro: uma análise sincrônica. Processo n. 2018/0773. Relatório final FAPESP. 2020.

CORADINI, M. C. As construções condicionais insubordinadas com a conjunção "se" no português sob uma perspectiva diacrônica. Relatório de Iniciação Científica. FAPESP, processo n. 2018/07734-3. São Carlos, 2020. 
DECAT, M. B. N. Uma abordagem funcionalista para o estudo de processos linguísticos em gêneros textuais do português em uso. Revista LinguíStica/Revista do Programa de Pós-Graduação em Linguística da Universidade Federal do Rio de Janeiro, v. 8, n. 1, p. 150162, jun. 2012. Disponível em: http://www.letras.ufrj.br/poslinguistica/revistalinguistica. Acesso em: 02 set. 2018.

DECAT, M. B. N. Estruturas desgarradas em língua portuguesa. Campinas: Pontes. 2011.

DECAT, M. B. N. Relações retóricas e funções textual-discursivas na articulação de orações no português brasileiro em uso. Calidoscópio, v. 8, n. 3, p. 167-173, set./dez. 2010.

DECAT, M. B. N. "Leite com manga morre": da hipotaxe adverbial no português em uso. 1993. Tese (Doutorado em Linguística Aplicada ao Ensino de Línguas) - Pontifícia Universidade Católica de São Paulo, São Paulo, 1993.

D'HERTEFELT, S. Insubordination in six Germanic languages. 2015. Tese (Doutorado em Linguística) - Katholieke Universiteit Leuven, Leuven, 2015.

EVANS, N. Insubordination and its uses. In: NIKOLAEVA, I. (ed.). Finiteness. Theoretical and Empirical Foundations. Oxford: Oxford University Press, 2007. p. 366-431.

GARCÍA, W. E. La prosodia de las construcciones insubordinadas conectivo-argumentativas em español. 2016. Tese. (Doutorado em Linguística) - Universidade de Barcelona, Barcelona, 2016.

GOLDBERG, A. Constructions: A Construction Grammar Approach to Argument Structure (Cognitive Theory of Language and Culture). Chicago: University of Chicago Press, 1995.

GOLDBERG, A. Constructions at Work: The Nature of Generalization in Language. Oxford: Oxford University Press, 2005.

GRAS, P. Revisiting the functional typology of insubordination: Insubordinate queconstructions in Spanish. In: EVANS, N., WATANABE, H. (ed.). Dynamics of Insubordination. Amsterdam: Benjamins, 2016. p. 113-144.

HIRATA-VALE, F. B. M. Polifuncionalidade do conectivo "que" no português do Brasil: uma análise construcional-interacional. Projeto de Pesquisa em andamento. 2020. 
HIRATA-VALE, F. B. M. Construções completivas insubordinadas no português: forma e função. Relatório Científico Final. Auxílio à pesquisa. FAPESP 2016/05224-2, 2018.

HIRATA-VALE, F. B. M. Construções condicionais insubordinadas no português: usos metatextuais. Estudos Linguísticos, v. 46, n. 1, p. 83-97, 2017.

HIRATA-VALE, F. B. M. O processo de insubordinação nas construções condicionais do português do Brasil. Relatório Científico Final. Bolsa de Pesquisa no Exterior. FAPESP: processo 13/24523-2, 2015.

HIRATA-VALE, F. B. M.; OLIVEIRA, T. P.; SILVA, C. F. Construções insubordinadas no português do Brasil: completivas e condicionais em análise. ODISSÉlA, v. 2, p. 25-41, 2017.

MITHUN, M. The extension of dependency beyond the sentence. Language, v. 84, n. 1, p. 69-119, 2008.

PIRES, C.; CORADINI, M. C. Construções condicionais insubordinadas adversativas: uma análise descritiva no português do brasil e sua comparação com o espanhol. Relatório Final. PIBIC/UFSCar. 2018.

SANSIÑENA, M. S. P. The multiple functional load of que: an interactional approach to insubordinate complement clauses in Spanish. 2015. PhD Thesis. Katholieke Universiteit Leuven, Leuven, 2015.

SANSIÑENA, M. S. P.; CORNILLIE, B.; DE SMET, H. Between subordinate and insubordinate. Complementizer-initial responses in English, French, German and Spanish. Trabalho apresentado no Complex Sentences International Workshop (CSI). 2013a. Disponível em: http://www.arts.kuleuven.be/ling/fest/events/np-3-2013-CSI-2013. Acesso em: 02 set. 2018.

SANSIÑENA, M. S. P.; CORNILLIE, B.; DE SMET, H. Free-standing que-clauses and other directive strategies in Spanish. Leuven Working papers in Linguistics. 2013b. Disponivel em: http://www.arts.kuleuven.be/ling/workingpapers/papers/pdf-files/LWPL7. Acesso em: 02 set. 2018.

SANSIÑENA, M. S.; DE SMET, H.; CORNILLIE, B. Between subordinate and insubordinate. Paths towards complementizer-initial main clauses. Journal of Pragmatics, v. 77, p. 3-9, 2015a. 
SANSIÑENA, M. S.; DE SMET, H.; CORNILLIE, B. Displaced directives. Subjunctive freestanding que-clauses vs. imperatives in Spanish. Folia Linguistica, v. 49, n. 1, p. 257-285, 2015b.

SILVESTRE, A. P. S. "Se eu pudesse e se o meu dinheiro desse...": Prosódia e Desgarramento no PB e no PE. 2017. Tese (Doutorado em Letras Vernáculas) - Faculdade de Letras, Universidade Federal do Rio de Janeiro, Rio de Janeiro, 2017.

STASSI-SÉ, J. Subordinação Discursiva no Português à luz da Gramática Discursivo-Funcional. 2012. Tese (Doutorado em Estudos Linguísticos) - Instituto de Biociências, Letras e Ciências Exatas, Universidade Estadual Paulista "Júlio de Mesquita Filho", São José do Rio Preto, 2012.

VAN LINDEN, A.; VAN DE VELDE, F. (Semi-)autonomous subordination in Dutch: Structures and semantic-pragmatic values. Journal of Pragmatics. http://dx.doi.org/10.1016/j. pragma.2013.08.022, 2013.

VERSTRAETE, J.; D'HERTEFELT, S.; VAN LINDEN, A. A typology of complement insubordination in Dutch. Studies in Language, n. 36, v. 1, p. 123-153, 2012.

VERSTRAETE, J. C.; D'HERTEFELT, S. Running in the family: Patterns of complement insubordination in Germanic. In: EVANS, N., WATANABE, H. (ed.). Dynamics of Insubordination. Amsterdam: Benjamins. 2016. p. 65-88. 